\title{
A dehydrin gene isolated from feral olive enhances drought tolerance in Arabidopsis transgenic plants
}

\author{
Adriana Chiappetta ${ }^{1}$, Antonella Muto ${ }^{1,2,3}$, Leonardo Bruno ${ }^{1}$, Magdalena Woloszynska ${ }^{2,3}$, \\ Mieke Van Lijsebettens ${ }^{2,3}$ and Maria B. Bitonti ${ }^{1 *}$ \\ 'Laboratory of Plant Biology, Department of Biology, Ecology and Earth Science, University of Calabria, Cosenza, Italy, \\ ${ }^{2}$ Department of Plant Systems Biology, VIB, Ghent University, Ghent, Belgium, ${ }^{3}$ Department of Plant Biotechnology and \\ Bioinformatics, Ghent University, Ghent, Belgium
}

OPEN ACCESS

Edited by:

John Love,

University of Exeter, UK

Reviewed by:

Kemal Kazan,

Commonwealth Scientific and Industrial Research Organization,

Australia

Mirza Hasanuzzaman Sher-e-Bangla Agricultural University, Bangladesh

*Correspondence: Maria B. Bitonti,

Laboratory of Plant Biology, Department of Biology, Ecology and Earth Science, University of Calabria,

Ponte P. Bucci, Cubo 6B, 87036 Arcavacata di Rende, Cosenza, Italy maria_beatrice.bitonti@unical.it

Specialty section This article was submitted to Plant Cell Biology, a section of the journal Frontiers in Plant Science

Received: 30 March 2015 Accepted: 16 May 2015 Published: 30 June 2015

Citation:

Chiappetta A, Muto A, Bruno L, Woloszynska M, Van Lijsebettens M and Bitonti MB (2015) A dehydrin

gene isolated from feral olive enhances drought tolerance in Arabidopsis transgenic plants. Front. Plant Sci. 6:392. doi: 10.3389/fpls.2015.00392
Dehydrins belong to a protein family whose expression may be induced or enhanced by developmental process and environmental stresses that lead to cell dehydration. A dehydrin gene named OesDHN was isolated and characterized from oleaster (Olea europaea L. subsp. europaea, var. sylvestris), the wild form of olive. To elucidate the contribution of OesDHN in the development of drought tolerance, its expression levels were investigated in oleaster plants during development and under drought stress condition. The involvement of OesDHN in plant stress response was also evaluated in Arabidopsis transgenic lines, engineered to overexpress this gene, and exposed to a controlled mild osmotic stress. OesDHN expression was found to be modulated during development and induced under mild drought stress in oleaster plants. In addition, the Arabidopsis transgenic plants showed a better tolerance to osmotic stress than wild-type plants. The results demonstrated that OesDHN expression is induced by drought stress and is able to confer osmotic stress tolerance. We suggest a role for OesDHN, as a putative functional marker of plant stress tolerance.

Keywords: dehydrins, drought tolerance, gene expression, oleaster, green fluorescent protein

\section{Introduction}

Due to their sessile organization, plants are exposed to wide diurnal, seasonal, and stochastic fluctuations. Consequently, plants developed a large spectrum of molecular programs to sense environmental changes rapidly and adapt accordingly (Sakuma et al., 2006; Meehl et al., 2007; Ahuja et al., 2010). However, despite this adaptive plasticity, in the last century the continuous anthropogenic impact and the ongoing climate changes negatively affected plant development and productivity (Zohary and Spiegel-Roy, 1975; Ceccarelli et al., 2007). Therefore, there is an increasing requirement to develop varieties with enhanced tolerance to multiple stresses, because in nature plants are often simultaneously exposed to several perturbations factors.

Understanding the reprogramming events that plants put in place in response to environment changes is of longstanding interest for plant biologist. Among defense mechanisms, a number of regulatory and/or protective proteins involved in plant tolerance to different stresses, have been identified (Choi et al., 1999; Skinner et al., 2005; Svensson et al., 2006; YamaguchiShinozaki and Shinozaki, 2006). Dehydrin proteins (DHNs) belong to these common protectants and their presence has been observed in several independent studies on drought, and salinity stresses as well as on cold acclimation and after abscisic acid (ABA) treatment 
(Close et al., 1989; Porat et al., 2004; Rorat et al., 2006; Tripepi et al., 2011). Therefore, they are referred also as RAB (responsive to ABA) and COR cold-regulated proteins (Close, 1996; Nylander et al., 2001).

DHNs are the group II, D 11 family of highly hydrophilic proteins, known as LEA (Late Embryogenesis Abundant), that accumulate in the late stages of embryogenesis, when water content in seeds declines, or in response to various stressors (Dure, 1993; Close, 1996, 1997; Battaglia et al., 2008). DHNs are intrinsically unstructured proteins and their molecular mass ranges from 9 to 70 kilo dalton $(\mathrm{kD})$ (Receveur-Bréchot et al., 2005; Graether and Boddington, 2014). Commonly, DHNs contain several conserved/identifiable motifs: the Y-segment, characterized by the consensus motif (T/V)D(E/Q)YGNP that is located near the $\mathrm{N}$-terminus, the $\mathrm{S}$-segment consisting of 5-7 Ser residues and the Lys-rich K-segment, usually located near the C-terminus, with an EKKGIMDIKEKLPG and $(\mathrm{Q} / \mathrm{E}) \mathrm{K}(\mathrm{P} / \mathrm{A}) \mathrm{G}(\mathrm{M} / \mathrm{L}) \mathrm{LDKIK}(\mathrm{A} / \mathrm{Q})(\mathrm{K} / \mathrm{M})(\mathrm{I} / \mathrm{L}) \mathrm{PG}$ motif in angiosperms and gymnosperms, respectively (Close et al., 1995; Allagulova et al., 2003; Receveur-Bréchot et al., 2005; Graether and Boddington, 2014). Recently, three dehydrin genes with the absence of a tipical K-segment were identified and characterized in Pinus pinaster (Perdiguero et al., 2014). Several others motifs have been suggested for DHNs, but their conservation and ubiquity have not yet been defined (Perdiguero et al., 2012; Graether and Boddington, 2014). On the basis of the number of Y-, S-, and K-segments that they individually contain, DHNs are classified into five subclasses: YnSK2, Kn, SKn, Y2Kn, and KnS (Mundy and Chua, 1988).

In plants DHNs are expressed in different tissues and organs (Rorat et al., 2004). In some cases DHNs activity is restricted to specific domains or cells within the organs, as in guard cells, meristematic cells or in pollen sacs (Nylander et al., 2001; Karlson et al., 2003; Rorat et al., 2004; Layton et al., 2010). At cellular level DHNs can be found commonly in the cytoplasm and the nucleus, but also at the level of plasmodesmata, mitochondria, chloroplast and near the plasma membrane (Danyluk et al., 1998; Hara et al., 2003; Graether and Boddington, 2014; Xu et al., 2014).

Phylogenetically widespread, $D H N s$ genes have been identified in cyanobacteria, algae, mosses, liverworts, lycopods and are ubiquitous in both angiosperms and gymnosperms species (Close, 1996, 1997; Campbell and Close, 1997; Allagulova et al., 2003; Layton et al., 2010). In the Arabidopsis proteome database 10 proteins bearing the typical DHN structure and 6 proteins with a K-segment-like sequence have been identified (Close, 1996; Bies-Etheve et al., 2008; Hundertmark and Hincha, 2008). Multiple DHN members have been also identified in different unrelated species and recently, 54 dehydrin unigenes have been identified in the Triticum genome (Velasco et al., 2007; Wang et al., 2007, 2014; Tommasini et al., 2008; Liu et al., 2012; Perdiguero et al., 2014).

According to the suggested involvement of DHNs in abiotic stress response, in several plants DHNs genes are induced under drought, cold and salinity (Porat et al., 2004; Lee et al., 2005). In addition, heterologous expression of DHNs genes, in different species, including relevant agronomic one such as rice, is associated with drought, cold and salinity tolerance (Hara et al.,
2003; Rorat et al., 2006; Choudhury et al., 2007; Brini et al., 2010). Therefore, the identification of new DHNs associated with drought tolerance may provide useful markers for the selection of drought-tolerant genotypes by either breeding or transformation technologies.

To meet such requirement, in the present work we isolated and characterized a $D H N$ gene from the wild form of olive, commonly named oleaster (Olea europaea L. subsp. europaea, var. sylvestris (Hoffm et Link). Oleaster is a typical and important shrub of vegetation present in the Mediterranean area, a climate region characterized by rainy winters and dry summers, with low air humidity, high solar radiation and high rates of evapotranspiration. Oleaster is largely prevalent in this habitat and displays a high photosynthetic efficiency and drought tolerance, related to its tap-root system that allows a deep exploration of the soil and a maximization of water uptake (Bacchetta et al., 2003; Mulas et al., 2011).

The oleaster identified gene, named OesDHN (Olea europaea subsp. europaea var. sylvestris DEHYDRIN), encodes a $\mathrm{SK}_{2-}$ typeDHN and its expression has been found to be upregulated in oleaster plants exposed to drought conditions. To elucidate the contribution of OesDHN in the development of drought tolerance, stable transgenic lines of Arabidopsis thaliana overexpressing this gene have been also developed. We show that under a mild osmotic stress, these Arabidopsis transgenic plants exhibit increased drought tolerance. The role of $\operatorname{Oes} D H N$, as a putative functional marker of plant stress tolerance is discussed.

\section{Materials and Methods}

\section{Isolation and Sequence Analyses of OesDHN}

The gene was identified in a cDNA library generated from leaves of oleaster plants, growing in open field in the Mediterranean area in South Italy ( 117 meter above sea level, $39^{\circ} 30^{\prime} 52.77^{\prime \prime} \mathrm{N} ; 15^{\circ} 56^{\prime}$ $28.83^{\prime} \mathrm{E}$ ). Leaves were collected in the summer, after a prolonged ( 2 weeks) period of high temperature $\left(35 \pm 2{ }^{\circ} \mathrm{C}\right)$. The cDNA library was generated using the SMART system and cloning the sequence (around $1.2 \mathrm{~kb}$ ) in the $\mathrm{pSPORT} 1$ vector. The sequencing analysis was performed from $5^{\prime}$ end. Generation and sequencing of the library was performed by Eurofins MWG GmbH cDNA Laboratory Fraunhoferstr (De) service.

\section{Genomic Organization of OesDHN}

Total genomic DNA (gDNA) was isolated from leaves of oleaster plants growing in open field. Samples were frozen in liquid nitrogen and processed according to CTAB extraction method (ctyltrimethylammonium bromide) (Murray and Thompson, 1980). Southern blots and hybridizations analysis were performed as described in Bruno et al. (2009).

Briefly, after extraction and purification, gDNA $(10 \mu \mathrm{g})$ was digested overnight at $37^{\circ} \mathrm{C}$ with $\mathrm{EcoRV}$ and $\mathrm{XbaI}$ endonucleases (Promega, Italy), which do not cut in the probe. The digested DNA fragments were separated on agarose gel $0.8 \%(\mathrm{w} / \mathrm{v})$ and blotted onto a nylon membrane Hybond-N+ (Amersham Pharmacia Biotech, Milan, Italy), using the Vacuum Blotting System (BioRad, Milan, Italy). Hybridization was performed with a specific probe, corresponding to the OesDHN ORF (Open 
Reading Frame), labeled with DIG-dNTPs (PCR Dig Probe Synthesis Kit; Roche Diagnostics, Monza, Italy). The detection was performed with nitro blue tetrazolium chloride (NBT) and 5-bromo-4-chloro-3-indolyl phosphate (BCIP) mixture, following the manufacturer's instructions (Roche, Monza, Italy) and hybridization signals were scanned with a computer (Umax Speed II).

The gDNA was also used in order to evaluate the putative presence of introns, using the following primers: FwORFOesDHN5' -ATGGCGGAGGAGGGACCCGTC-3'; BwORFOesDHN: 5'-TTAGTGGCATGCCCCCTCCTT-3'.

\section{Isolation of the $5^{\prime}$-Flanking Region of OesDHN}

The OesDHN promoter region was obtained by using the "Universal GenomeWalker ${ }^{\mathrm{TM}}$ kit" (Clontech, Diatech lab line, Milan, Italy) with some modifications. The purified gDNA was digested with four different blunt-ended restriction enzymes (DraI, EcoRV, Pvu II, Stu I) and the products were purified and ligated, separately, to "Genome Walker adaptors," in order to produce four libraries. Two gene specific primers were used for the amplification of the promoter region. For the primary PCR (PCRI) were used: an AP1 primer (outer Adapter Primer), provided by the kit, a GSP1 primer (Gene Specific Primer 1; $5^{\prime}$ TTTCTTCTTCCTTGTGCTCCGGTTCACA-3') and the ligated products as template. The thermal cycling program was $94^{\circ} \mathrm{C}$ for $25 \mathrm{~s}$ and $72^{\circ} \mathrm{C}$ for $3 \mathrm{~min} ; 7$ cycles were used followed by 32 cycles of $94^{\circ} \mathrm{C}$ for $25 \mathrm{~s}$ and $67^{\circ} \mathrm{C}$ for $3 \mathrm{~min}$, with a final extension at $67^{\circ} \mathrm{C}$ for $3 \mathrm{~min}$. The products of the PCRI were then diluted and used as template for the secondary PCR (PCRII), using an AP2 primer (nested Adapter Primer 2) provided by the kit, and a GSP2 primer (Gene Specific Primer 2; $5^{\prime}$ CCC TGAAATCAAACAACCCACGGTCCT-3'). For the PCRII the used parameters were 5 cycles of $94^{\circ} \mathrm{C}$ for $25 \mathrm{~s}$ and $72^{\circ} \mathrm{C}$ for $3 \mathrm{~min}$, followed by 20 cycles of $94^{\circ} \mathrm{C}$ for $25 \mathrm{~s}$ and $67^{\circ} \mathrm{C}$ for $3 \mathrm{~min}$, with a final extension at $67^{\circ} \mathrm{C}$ for $7 \mathrm{~min}$. PCR amplifications were performed on a Step One machine (Applied Biosystems, Monza, Italy) and products were sequenced by GENELab laboratory (ENEA, Rome).

\section{Alignments and Phylogenetics Analysis}

OesDHN amino acid sequence was obtained using the ExPASy Proteomic Tools (http://www.expasy.org/tools/dna.html) program. The analysis and the comparison of OesDHN deduced amino acid sequence with other dehydrin proteins were performed with blastp (Standard Protein-Protein BLAST) (http://blast.ncbi.nlm.nih.gov/Blast.cgi?PROGRAM=blastp\&PA GE_TYPE=BlastSearch\&LINK_LOC=blasthome) program. OesDHN sequence was aligned with other plant dehydrins using the ClustalW2 program (http://www.ebi.ac.uk/Tools/ msa/clustalw2/). A phylogenetic tree was generated by the MEGA4 software (Molecular Evolutionary Genetics Analysis) (Tamura et al., 2007) with bootstrap values obtained from 1000 replications and using the listed protein sequence: Arabidopsis thaliana COR47 (P31168), Arabidopsis thaliana ERD10 (P42759), Arabidopsis thaliana ERD14 (P42763), Arabidopsis thaliana DHLEA or PAP310, (Q96261), Arabidopsis thaliana Q9SLJ2 (At1g54410), Arabidopsis thaliana Q9SVE4 (75313932),
Arabidopsis thaliana Q9T022, Arabidopsis thaliana RAB18 (P30185), Arabidopsis thaliana XERO1 (P42758), Arabidopsis thaliana XERO2 (P42758), Avicennia marina AmDHN1 (A8CVF3), Brassica juncea DHN2 (ABD95986), Brassica oleracea BOPC34 (CAA64428), Citrus trifoliata COR11 (AAA99963.1), Craterostigma plantagineum (P22238), Glycine max MAT9 (AAA33992), Hordeum vulgare subsp. vulgare DHN1(P12951), Hordeum vulgare subsp. vulgare DHN5 (AAF01693), Hordeum vulgare subsp. vulgare PAF93 (CAA58875), Jatropha curcas JcDHN-1 (ADT65200), Medicago sativa G2 (AEV52291), Medicago sativa subsp. falcata CAS18 (AAA21185), Opuntia streptacantha DHN1 (AEI52546), Oryza sativa Japonica WSI724 (BAA05539), Oryza sativa Japonica DH16D or RAB16D (P22913), Pisum sativum DHN2 (CAA44788), Pisum sativum dhn-cog (CAA78515), Populus alba $x$ Populus glandulosa PoDHN (ABH11546), Prunus persica DHN1 (P28639), Prunus persica PCA60 (AAC49657), Rhododendron catawbiense DHN-5 (ACB41781), Solanum sogarandinum DHN24 (AAP44575), Triticum aestivum COR410 (P46524), Triticum aestivum CS120(P46525), Triticum aestivum CS66 (P46526), Triticum aestivum RAB15 or DHR15 (Q00742), Vitis vinifera DHN1b (526118232), Zea mays COR410 Zea mays (226532837), Zea mays DEHYDRIN 13 (EU962627.1), Zea mays DHN1 (18963), Zea mays lipase DHN2 (L35913.1), Zea mays Put. unch. protein (219363418), Zea mays RAB17 (18963). Analysis of targeting sequences was performed using PSORT (http://psort.nibb.ac.jp/) and Wolf PSORT (http://wolfpsort.seq.cbrc.jp/) programs.

\section{Drought Assay in OLEASTER Plants}

Drought stress was performed on 2 years old oleaster plants $(n=$ 10) obtained through micropropagation and grown in pots on standard sandy loam soil and daily irrigation. Drought condition was applied by depriving progressively the plants of water content as described by Tommasini et al. (2008). The soil water content (SWC) was calculated relative to $100 \%$ water capacity of soil by weighing plant at different times. We considered the $100 \%$ SWC the weight of plants wetted until saturation, covered with parafilm at the soil surface and drained for $1 \mathrm{~h}$. These samples were used as control.

For drought stress samples were collected when SWC values were approximatively the $45 \%$, the mild drought stress, and $37 \%$, the high drought stress, reached after 14 and 35 days, respectively.

\section{qRT-PCR in OLEASTER Plants}

qRT-PCR analysis was performed: (i) on oleaster plants $(n=5)$ growing in open field in the Mediterranean area, in South of Italy (117 meter above sea level, $39^{\circ} 30^{\prime} 52.77^{\prime \prime} \mathrm{N} ; 15^{\circ} 56^{\prime} 28.83^{\prime} \mathrm{E}$ ). In this case different organs were analyzed: apical vegetative shoot, young $(1-2 \mathrm{~cm})$ and adult $(6-8 \mathrm{~cm})$ leaves, stem (harvested at the resumption of the vegetative growth) and green drupes; (ii) on mature leaves $(2.5 \mathrm{~cm})$ and stem of 2 years old oleaster plants, $(n=10)$, exposed to drought assay.

For both groups, excised organs were immediately frozen. Total RNA was isolated from $100 \mathrm{mg}$ of oleaster samples, using the RNeasy Plant Mini kit (Qiagen, Hilden, Germany), as previously described by Bruno et al. (2009). One microgram of total RNA was used to generate the single-strand cDNA by 
the SuperScript III Reverse Transcriptase and the oligodT(20), following manufacturer's instructions (Invitrogen, Milan, Italy). The cDNA concentration was determined by the NanoDrop Spectrophotometer ND-1000.

A Step One single color thermocycler (Applied Biosystems, Monza, Italy) with Power SYBR Green PCRMaster Mix 2X (Applied Biosystem, Monza, Italy) (Cat. no. 4368702) were utilized. The primer sets used, the OesDHN FW $5^{\prime}$-AAG GAG AAG CTC CCT GGG TA $-3^{\prime}$ and OesDHN BW $5^{\prime}$ AAA CCA CCA AAG AAG AAA TCA AA $-3^{\prime}$ were designed using the Primer3 (http://primer3.ut.ee/) program, according to Yokoyama and Nishitani (2001). The olive 18S histone was used as a normalization control. The Oes $18 \mathrm{~S}$ primer sequences were Oes18S FW 5'-CAG CCT TCA ATG ATC GGA AT$3^{\prime}$ and Oes18S BW 5'GCG CTG TAA TTT CCT TGC TC. Amplification reactions were prepared in a final volume of $25 \mathrm{ml}$ by adding $12.5 \mathrm{ml}$ of the iTaq SYBR-Green Super Mix with ROX (Bio-Rad, Milan, Italy), $1 \mathrm{ml}(0.4 \mathrm{mM})$ of primers, and $2 \mathrm{ml}$ $(25 \mathrm{ng})$ of cDNA. All reactions were run in triplicate, in 48well reaction plates, and negative controls were set. The cycling parameters were performed as described in Bruno et al. (2014). The quantitative qRT-PCR data were analyzed using the Step One Software 2.0 (Applied Biosystems, Monza, Italy) with the $2^{-\Delta \Delta C T}$ method (Livak and Schmittgen, 2001). The means of OesDHN expression levels were calculated from three biological repeats, obtained from three independent experiments.

\section{Histological Analysis}

Mature leaves $(n=15)$ collected from stressed and unstressed plants were fixed in $3 \%(\mathrm{w} / \mathrm{v})$ paraformaldehyde and $0.5 \%$ (v/v) glutaraldehyde in PBS buffer $(135 \mathrm{mM} \mathrm{NaCl}, 2.7 \mathrm{mM} \mathrm{KCl}$, $1.5 \mathrm{mM} \mathrm{KH} 2 \mathrm{PO} 4,8 \mathrm{mM}$ K2HPO4 $\mathrm{pH} 7.3$ ) for $3 \mathrm{~h}$ at $4{ }^{\circ} \mathrm{C}$. After washing in the same buffer, samples were dehydrated and embedded in Tecknovitt 8100 resin Heraeus Kulzer (Germany). Semi-thin sections $(4 \mu \mathrm{m})$ were obtained using an ultracut microtome (Leica RM 2155, Milan, Italy) and stained with toluidine blue $\mathrm{O} 0.05 \%$ in distilled water.

The histological samples were analyzed by bright-field illumination (Leica DRMB, Milan, Italy) and images were taken with the digital camera Leica DFC 320 (Leica, Milan, Italy).

\section{Dehydrins Immunolocalization}

Dehydrins immunolocalization was performed as described in Carjuzaa et al. (2008). Mature leaves $(n=15)$ were collected from stressed and unstressed plants and fixed in $2 \%$ $(\mathrm{w} / \mathrm{v})$ paraformaldehyde and $1 \%(\mathrm{v} / \mathrm{v})$ glutaraldehyde in $0.1 \mathrm{M}$ phosphate buffer, ph7.2 for $2 \mathrm{~h}$ at $4^{\circ} \mathrm{C}$. Samples were washed with deionized water for $30 \mathrm{~min}$, dehydrated and embedded in paraplast (Sigma-Aldrich, Milan, Italy). Afterwards, they were cut with an RM 2125 RT microtome (Leica, Milan, Italy) into $8 \mu \mathrm{m}$ sections that were transferred to charged slides and incubated with anti-dehydrin primary antibody (LiStarFish, Milan, Italy) diluited 1:200 at $4^{\circ} \mathrm{C}$ overnight. Subsequently, sections were incubated with goat anti-rabbit IgG alkaline phosphate conjugate, (Calbiochem, Milan, Italy) diluted 1:100 for $4 \mathrm{~h}$ at $4^{\circ} \mathrm{C}$. After washing, the sections were developed with a NBT (nitro blue tetrazolium) and BCIP (5-bromo4-chloro-3-indolylphosphate) mixture, for $5 \mathrm{~min}$, rinsed and immediately observed with a Leica DRMB microscope (Leica, Milan, Italy) equipped with a Leica DFC 320 camera. To verify the effectiveness of the immunolocalization technique, sections were processed with the omission of the primary anti-dehydrin antibody.

\section{Recombinant Constructs using the Gateway Technology}

OesDHN cDNA, obtained as previously described, was cloned into the pDONOR221(Invitrogen) plasmid using the Gateway method. The sequence captured as entry clone was recombined in both pK7WG2 and pKF7WG2/pK7WGF2 vectors (Karimi et al., 2002) for OesDHN overexpression analysis and for its localization in $\mathrm{N}$ - and $\mathrm{C}$ - terminal with the green fluorescent protein (GFP) fusion, respectively, under the control of the cauliflower mosaic virus 35Spromoter.

For Gateway the following primers were used: FWattB1 ORFnoSTOP:5'GGGGACAAGTTTGTACAAAAAAGCAG GCTTCATGGCGGAGGAGGGACCCGTC-3'; BWattB2plus STOP:5'-GGGGACCACTTTGTACAAGAAAGCTGGGTCTT AGTGGCATGCCCCCTCCTT-3'; BWattB2noSTOP:5'-GGGG ACCACTTTGTACAAGAAAGCTGGGTCGTGGCATGCC CCCTCCTT-3'; FWattB1 5'-GGGGACAAGTTTGTACAAAA AAGCAGGCT-3; BWattB25' -GGGGACCACTTTGTACAAG AAAGCTGGGT-3'.

The constructs are schematized in Figure 1S. They were sequenced by GENELab (ENEA, Rome), transferred into Agrobacterium tumefaciens (GV3101) by heat shock and used to transform Arabidopsis thaliana accession Col-0 plants by floral dipping (Clough and Bent, 1998; Davis et al., 2009).

\section{Selection and qRT-PCR of Arabidopsis Transgenic Lines}

Arabidopsis Col-0 seedlings were grown in vitro on Murashige and Skoog (MS) medium (Murashige and Skoog, 1962) plus vitamins (Sigma, Milan, Italy), supplemented with $0.1 \mathrm{~g} / \mathrm{l}$ of myoinositol, $0.5 \mathrm{~g} / \mathrm{l}$ of 2-N-morpholine ethane sulphonic acid (MES), $10 \mathrm{~g} / \mathrm{l}$ sucrose and $8 \mathrm{~g} / \mathrm{l}$ agar, $\mathrm{pH}$ of 5.7. Plants were grown under $16 \mathrm{~h}$ day at $22^{\circ} \mathrm{C}$ and $8 \mathrm{~h}$ night at $18^{\circ} \mathrm{C}$ regime, light intensity was $100 \mu \mathrm{mol} \mathrm{m} \mathrm{m}^{-2} \mathrm{~s}^{-1}$ and the relative humidity (RH) was 65-70\%.

Arabidopsis transgenic lines were selected on a MS medium plus vitamins, supplemented with $50 \mu \mathrm{g} / \mathrm{ml}$ Kanamycin $(\mathrm{Km})$, $250 \mu \mathrm{g} / \mathrm{ml}$ di Carbenocillin (Cb) and $50 \mu \mathrm{g} / \mathrm{ml}$ Nystatin (Ns) or with only $50 \mu \mathrm{g} / \mathrm{ml} \mathrm{Km}$.

The number of T-DNA loci for each line was determined by chi-square statistical method. The presence of the transgene, in T3 homozygous lines with 1 T-DNA locus, was confirmed through qRT-PCR, using at least three pairs of gene specific primers (FW1OesDHNRT:5'-CTGGTGAGCACAAGGAAGAA-3; BW1OesDHNRT: 5'TGGTGCAGAAACTTCCTCAG-3'; FW2Oes DHNRT:5'-CTGAGGAAGTTTCTGCACCA-3'; BW2OesDHNRT: 5'-TCTCCTTTGCCTCAACGTC-3'; FW3OesDHNRT:5'-TGGG TTGTTTGATTTCATGG-3; BW3OesDHNRT: $\quad 5^{\prime}$-CTTCCT TGTGCTCCGGTT-3', located at different points of the ORF 
and designed by GenScript Real-time Primer Design program (https://www.genscript.com/ssl-bin/app/primer).

The qRT-PCR was performed by the LightCycler 480 machine (Roche Diagnostics) according to the manual and the parameters of annealing and extension were: 45 cycles of $95^{\circ} \mathrm{C}$ for $10 \mathrm{~min}, 60^{\circ} \mathrm{C}$ for $50 \mathrm{~s}, 72^{\circ} \mathrm{C}$ for $50 \mathrm{~s}$. The reaction mix was prepared by using a robotic platform (JANUS, Perkin Elmer, Massachusetts, USA). The melting curves were performed to analyze the specificity of primers. Normalization was performed using the followed housekeeping genes: SAND family (AT2G28390), TIP41-like (AT4G34270), UBC (AT5G25760) and PP2A subunits (AT1G13320) and primers (FWSAND family: 5'-AACTCTATGCAGCATTTGATCCACT-3'; BWSAND family: 5'-TGATTGCATATCTTTATCGCCATC-3'; FWTIP41-like:5' GTGAAAACTGTTGGAGAGAAGCAA-3'; BWTIP41-like: 5' -TCAACTGGATACCCTTTCGCA-3'; FWPP2A subunit: 5'-AACTCTATGCAGCATTTGATCCACT-3'; BWPP2A subunit: $5^{\prime}$-TGATTGCATATCTTTATCGCCATC-3'; FWUBC: $5^{\prime}$ CTGCGACTCAG $\hat{G} G A A T C T T C T A A-3^{\prime}$; BWUBC: 5'-TTGTGCC ATTGAATTGAACCC-3'; (Czechowski et al., 2005). The results were analyzed using the LightCycler software with the $2^{-\Delta \Delta C T}$ method (Livak and Schmittgen, 2001). The Ct-values were calculated from three biological replicates, obtained from three independent experiments.

\section{Osmotic Assay in Arabidopsis 35S::OesDHN Transgenic Plants}

Sixteen seedlings of transgenic line, 35S::OesDHN B1-2, with high transgene expression were germinated on MS medium containing mannitol $25 \mathrm{mM}$ (Sigma, Milan, Italy) and leaves were harvested after 22 days. Leaves were dissected under a stereomicroscope, placed in square plates on $1 \%(\mathrm{w} / \mathrm{v})$ plant tissue agar, and then photographed. Length and leaf area were measured by ImageJ program (rsbweb.nih.gov/ /ijdownload.html) and mean values of three independent experiments were subjected to statistical analysis.

\section{Confocal Microscopy}

Confocal analysis were performed on 6 old days Arabidopsis seedlings of T3 35S::OesDHN:GFP line A 4-1, 35S::GFP:OesDHN line C11-5 and Col-0 plants grown in vitro, in vertical position and under continuous light regime. Samples were mounted in water and observed under a confocal microscope $100 \mathrm{M}$ Zeiss (Zeiss, Germany), equipped with the software package LSM 510 version 3.2. Excitation and emission wavelenghts used were 488-nm and 500-550-nm band-pass filter. Chlorophyll autofluorescence was imaged using $488 \mathrm{~nm}$ for excitation and $633 \mathrm{~nm}$ for emission. The green and red autofluorescence were collected in separate channels.

\section{Sequences Deposition}

The sequence obtained in this study was submitted to the GenBank with the following accession number: KR349290.

\section{Results}

\section{Genomic Organization of OesDHN and Analysis of its 5'Flanking Region}

OesDHN was identified from a cDNA full length library, generated from total RNA of oleaster leaves harvested in summer, after a prolonged periods ( 2 weeks) of high temperatures ( $T_{\text {Max }}=$ $35 \pm 2^{\circ} \mathrm{C} ; T_{\text {Min }}=26.5 \pm 2^{\circ} \mathrm{C}$ ). The generated 1200 unigenes were functionally annotated based to the best BLASTX hit, against the NCBI database with a cut-off of $E<10-15$. A large number of genes (40\%), corresponding to stress-responsive gene were identified, and among these we selected a member of $D H N$ gene family.

The full-length cDNA of OesDHN was $1207 \mathrm{bp}$ long and showed an ORF of 636 and a 31 bp $5^{\prime}$-UTR and a $540 \mathrm{bp} \mathrm{3'-}$ UTR regions. Comparison of genomic and cDNA sequence and T BLASTX analysis showed that the OesDHN gene contained a single intron of $95 \mathrm{bp}$ (Figure 1A).

To determine the copy number of OesDHN gene in the oleaster genome we performed a southern blot analysis using the $636 \mathrm{bp}$ cDNA fragment as probe. After gDNA digestion by $E c o R I$ and $X b a I$ the hybridization pattern showed two crosshybridizing bands, suggesting that at least two copies are present in the oleaster genome (Figure 1B).

We also isolated a $676 \mathrm{bp} O e s D H N$ promoter region. Analysis of its sequence, using the "PLACE" and "PlantCARE" databases (Lescot et al., 2002), revealed the presence of a TATA-box sequence, located $69 \mathrm{bp}$ upstream of the translational start site (TSS) (Figure 1C). As reported for many dehydratationresponsive genes (Zhu, 2002), the $5^{\prime}$ region contained putative cis-regulatory sequences, such as an ABA-responsive element (ACGT sequences) also named ABRE and a G-box (CACGTT) element identified at the $-631 \mathrm{bp}$ position, and two MYB-binding consensus sequences (WAACCA) located at -502 and $-264 \mathrm{bp}$ upstream the TSS, respectively Furthermore, two GATA boxes regulatory elements, with homology to those identified in lightresponsive genes, were detected at the position -497 and $-438 \mathrm{bp}$. Finally, a CAAT-box (C-box), a common cis-enhancer promoter region, was identified at the position -586 (Figure 1C).

\section{Characterization and Phylogenetic Analysis of Deduced OesDHN}

OesDHN encodes a putative protein of 211 amino acids, with a predicted molecular weight of $241 \mathrm{kDa}$ and an isoelectric point of 53 (Geneious 7.1.5). The multiple amino acid sequence alignment revealed that OesDHN shares all common features of plant DHNs family (Figure 1C). Namely, a conserved region with serine residues, the S-segment, was located between the residues 66 and 80 and two lysine-rich consensus motifs, the K-segments, were present between the residues 126-140 and 171-185, respectively, closed to the C-terminal region. As showed for other plant DHNs, a putative nuclear localization signal peptide (NLS), identified by the KKKK sequence, was located between the 90-93 residues downstream the S segment (Figure 1C). Finally, a poly-proline cluster, an important component of intrinsically unstructured proteins (Rath et al., 2005; Harauz and Libich, 2009), was located at residues 151-156 between the K segments (Figure 1C). 
A

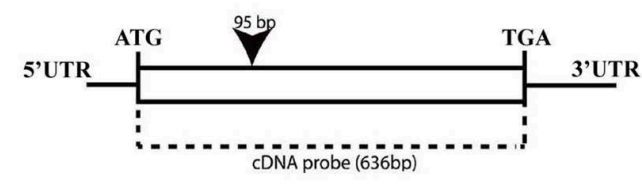

B

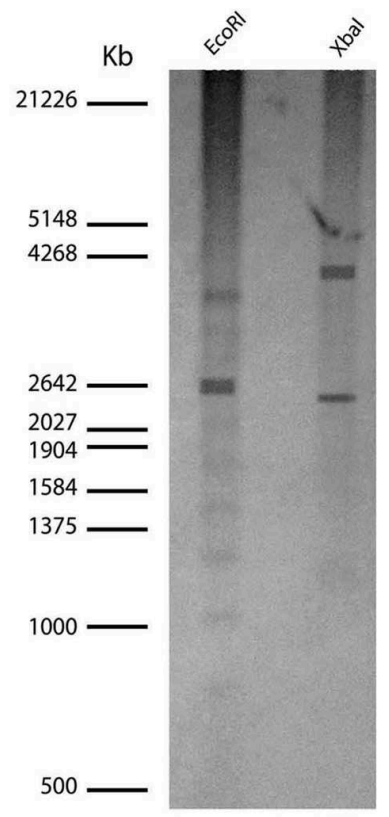

C

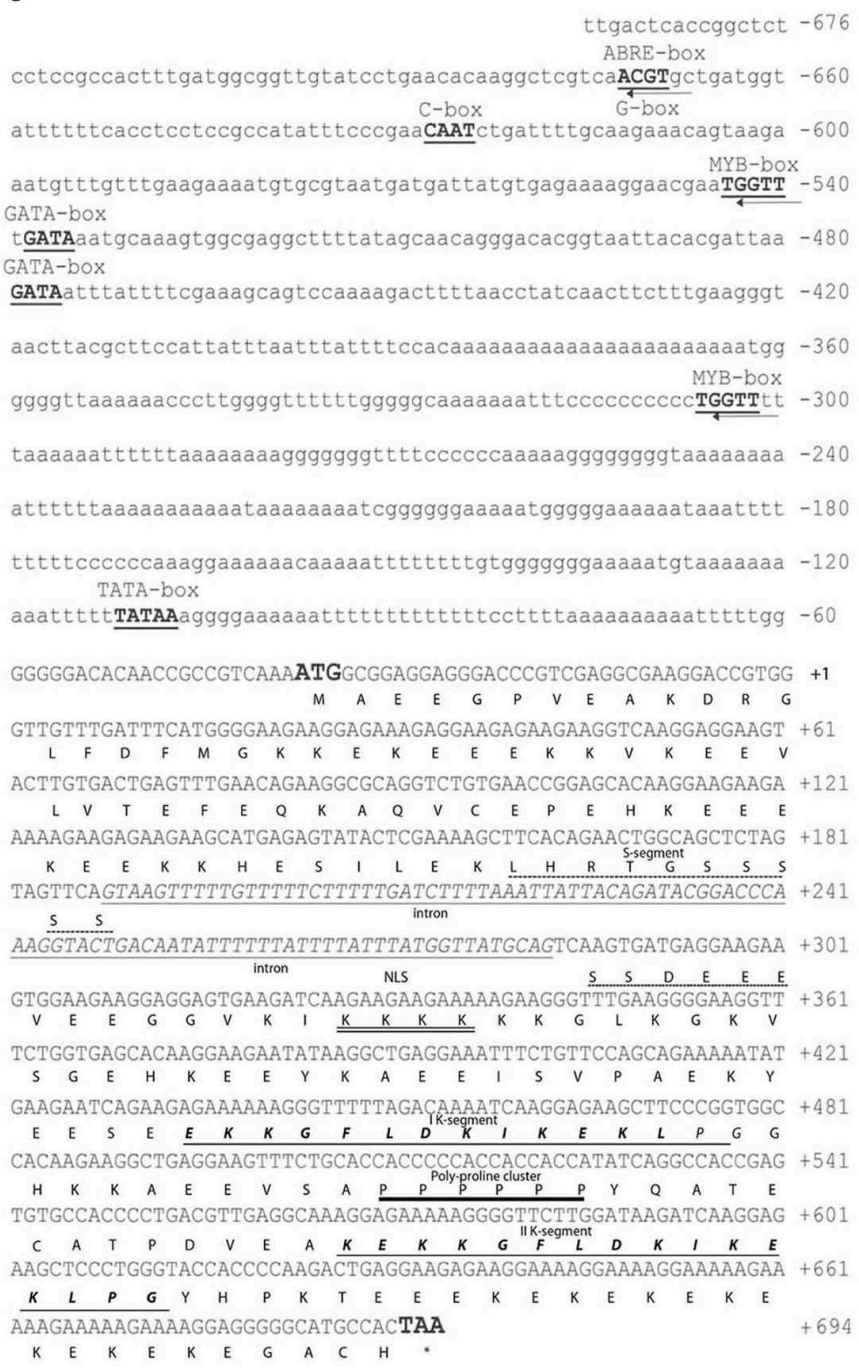

FIGURE 1 | OesDHN genomic organization. (A) Scheme of OesDHN gene. The black rectangle indicates intron position with respect to the cDNA. Start and stop codons are typed. (C) Deduced nucleotides of OesDHN cDNA and its $5^{\prime}$ upstream region and features of OesDHN protein. The ATG start and TAA stop codons are indicated in bold; the stop codon position is indicated by the asterisk. The intron sequence, including the putative TATA-box (bold) is highlighted. The putative ABRE, G-box, MYB, GATA, CAAT-box elements are also indicated. Predicted amino acids are shown in one letter code. The
S-segment is shown with an interrupted line, and the two K-segments are shown in bold italics and underlined with a single line. The putative NLS (nuclear localization signal) is double underlined and the poly-proline cluster is shown with one single line. The intronic region is represented with italic lowercases. (B) Southern blot analysis. The oleaster gDNA was digested with ECORI and Xbal and hybridized with the cDNA probe, indicated in (A). The molecular weights of a co-migrating DNA marker are expressed in kilo base pairs (Kb). PR, promoter region; UTR, Untranslated region. Bar $200 \mathrm{bp}$ (A).
The OesDHN deduced protein exhibited a significant degree of amino acid sequence identity with known homologs, i.e., $63 \%$ identity and $73 \%$ similarity with DHN of Solanum chilense, by $60 \%$ identity and $67 \%$ similarity with BDN1 of Paraboea crassifolia, $50 \%$ identity and $70 \%$ similarity with Populus maximowiczii, 56\% identity and $68 \%$ similarity with Coffea canephora, and 52\% identity and 66\% similarity with DHN in Citrus $x$ paradise (50\%) (Figure 2).

A phylogenetic tree, using YnSKn, SKn, Kn, YnKn, and KnS- type DHNs indicated that OesDHN clustered together with $\mathrm{SK}_{n}$-type dehydrins (Figure 3). Thus, the results of both homology and phylogenetic analyses suggest that OesDHN is an $\mathrm{SK}_{2}$-type DHN.

\section{In OLEASTER Plants OesDHN Is Modulated During Development and Induced under Drought Stress Condition}

Tissue specific OesDHN expression was analyzed through qRTPCR in oleaster plants grown in open field (Figure 4A). OesDHN expression was observed in all examined tissues, although at different level. Indeed, transcript accumulation OesDHN was 


\section{OesDHN \\ Solanum chilense Paraboea crassifolia Populus maximowiczii Coffea canephora Citrus $\mathrm{x}$ paradisi}
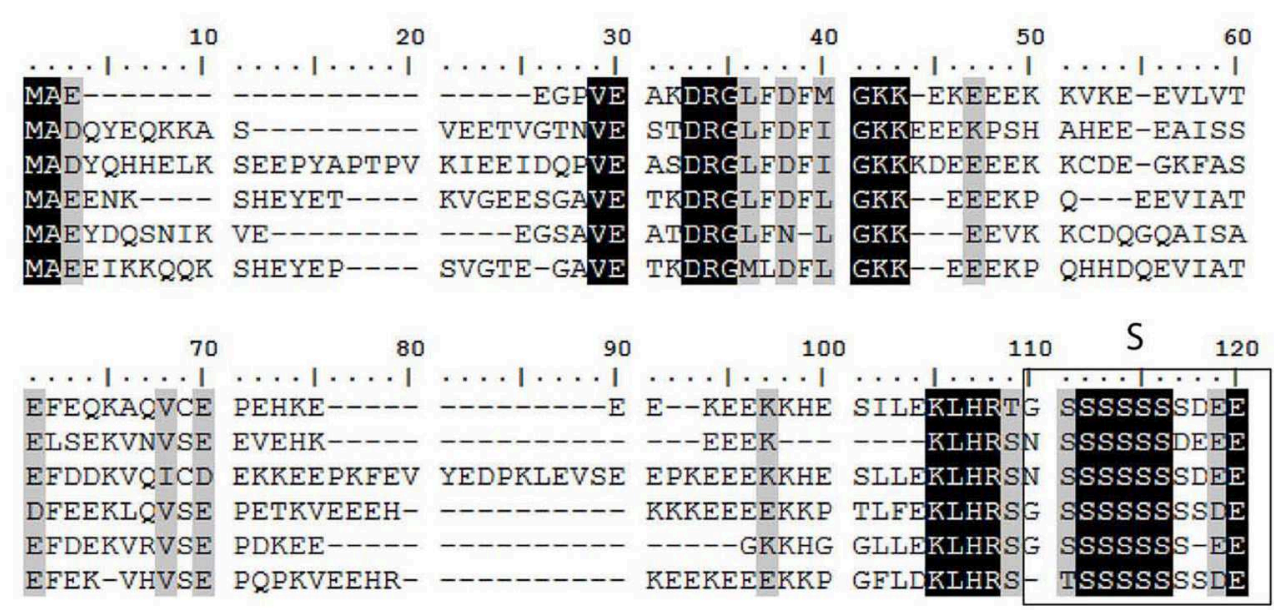

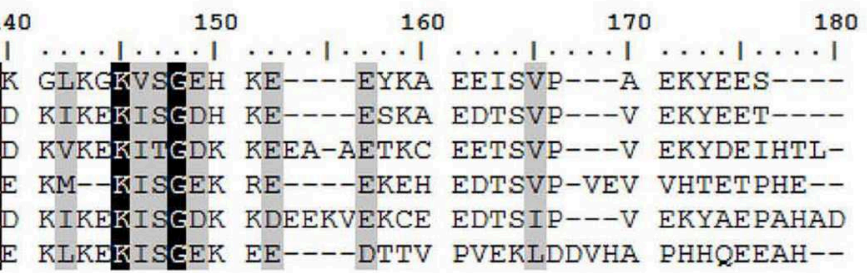
KLKEKISGEK EE----DTTV PVERLDDVHA PHHQEEAH--

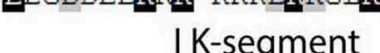

I K-segment
200

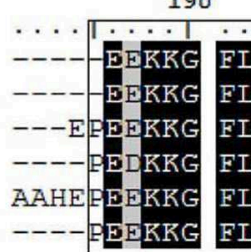

----PEEKKG

\begin{abstract}
OesDHN
Solanum chilense

Paraboea crassifolia Populus maximowiczii Coffea canephora Citrus $x$ paradisi
\end{abstract}

\section{OesDHN}

Solanum chilense Paraboea crassifolia Populus maximowiczii Coffea canephora Citrus $x$ paradisi

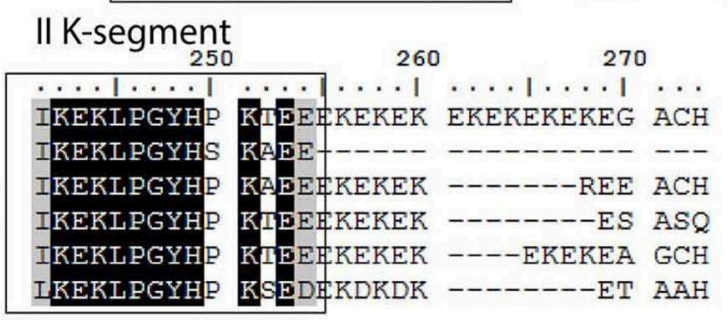

(ABS12346.1), Coffea canephora (ABC68275.1), and Citrus $x$ paradise (AAN78125.1). The multiple amino acid sequence alignment reveals the common features of OesDHN with plant dehydrin family, such as the S- and $\mathrm{K}$ - segment, that are boxed.
FIGURE 2 | Sequence alignment of OesDHN protein with homologs from other plant species performed with the NCBI database. Accession numbers are given in parentheses: Solanum chilense (ADQ73953.1), Paraboea crassifolia (AAF014652.2), Populus maximowiczii

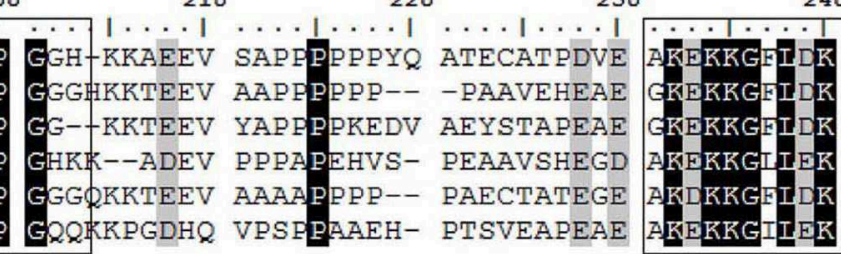

K-segment 40 

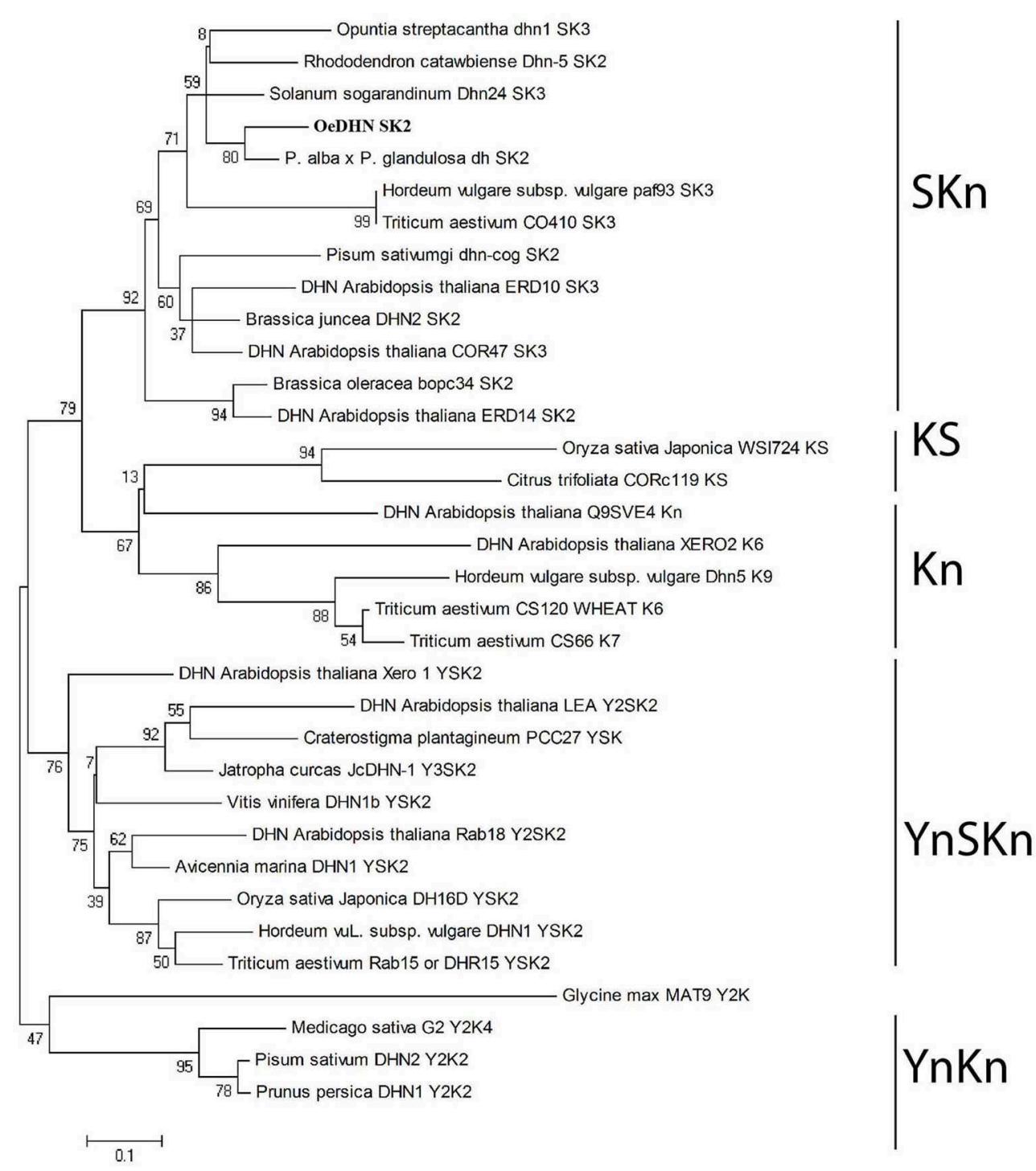

FIGURE 3 | Phylogenetic tree of DHN proteins. The neighbor-joining tree was generated using the MEGA4 (www.megasoftware.net) version 5.0 software, with bootstrap value obtained from 1000 replications.

(37\% SWC) cells featured clearly plasmolyzed and mesophyll exhibited wide intercellular spaces although leaf collapse was prevented thanks to the presence of numerous sclerenchyma fibers (Figures 4E,F).

All together these results demonstrated that OesDHN expression is modulated during development and induced under mild drought stress.

Immuocytological assay allowed us to verify that DHNs accumulate under drought stress in oleaster leaves and exhibit both a cytosol and nuclear localization (Figure 2S).

\section{Overexpression of OesDHN Improves Osmotic Stress Tolerance in Arabidopsis Transgenic Lines} To confirm the involvement of OesDHN in plant stress response, Arabidopsis 35S::OesDHN lines were generated and the effects of a controlled mild osmotic stress (Skirycz et al., 2010) were analyzed using Arabidopsis 35S::OesDHN T3 B1-2 and 35S::OesDHN T3 B9-7 transgenic lines, with highest transgene expression (Figure 5A). We report the results obtained with the 35S::OesDHN T3 B1-2 (Figures 5B-E).

Leaf series were made of seedling rosettes, 22 days after germination and before bolting and leaf area was measured (Figures 5F-I). Under normal conditions, no difference in leaf area was observed between the transgenic line and wild type with the exception of leaf 7, 8, and 9 (Figures 5F,H). Under mannitol stress $25 \mathrm{mM}$ leaf size was constantly and significantly higher in transgenic line compared to the control (Figures 5D,E,G,I). The strongest effects were observed on 4 and 5 leaves that in $35 \mathrm{~S}::$ OesDHN B 1-2 line were respectively 15 and 10\%, larger then control (Figures 5G,I). 


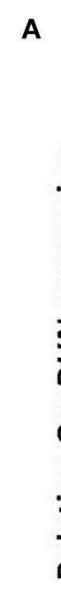

$$
\text { A }
$$
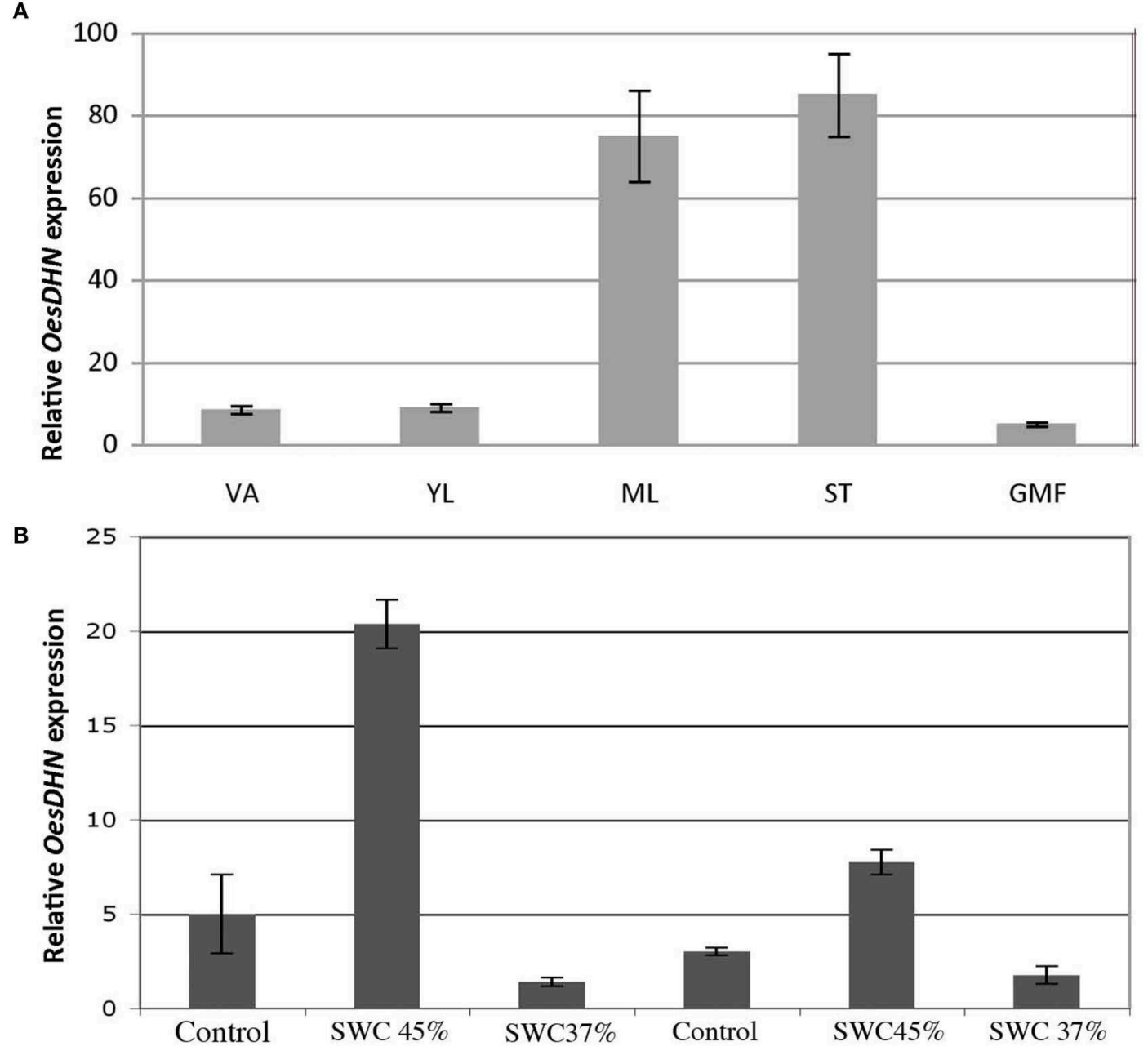

leaves

stem

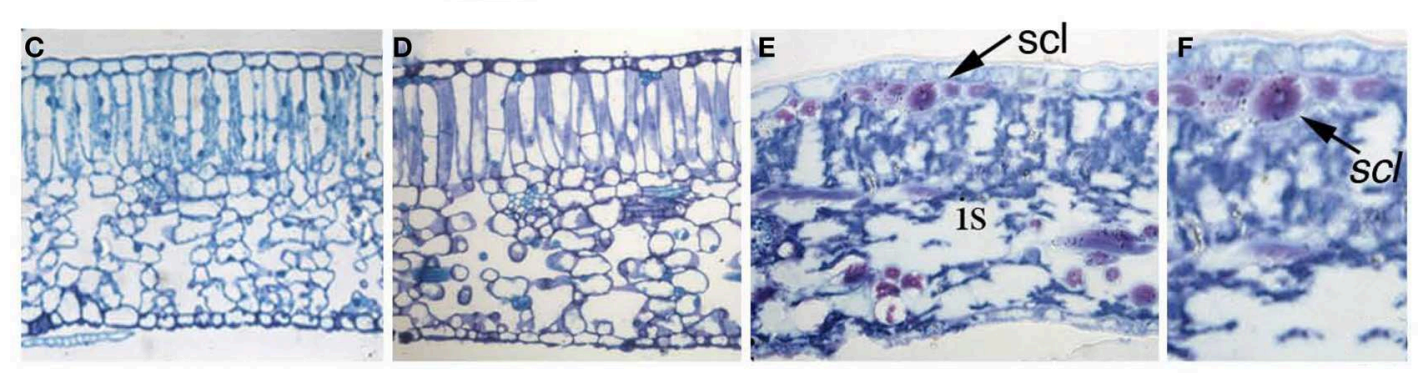

FIGURE 4 | (A) Relative expression levels of OesDHN, estimated by qRT-PCR, in different organs of Olea europaea L. subsp. europaea var. sylvestris grown in open field and (B) grown in pots and exposed to a SWC of 45 and $37 \%$. The levels of OesDHN were normalized to Oes18S histone. Data shown are averages of three biological replicates, with error bars representing SD. (C-F) Cross sections of mature leaves (length $2.5 \pm 0.3 \mathrm{~cm}$ ) of oleaster plants grown in pots under control condition (C) and exposed to a soil water content (SWC) of $45 \%$ (D) and $37 \%$ (E,F). VA, Vegetative apex; YL, young leaves; ML, mature leaves; ST, Stem; GMF, green mature fruit; is, intercellular spaces; scl, sclerenchyma fibers. Arrow indicates sclerenchyma fibers. Bars $25 \mu \mathrm{m}$ (C-E); $43 \mu \mathrm{m}$ (F).
These results suggest that the growth of Arabidopsis 35S::OesDHN plants, under a mild osmotic stress, is less inhibited by mannitol treatment as compared to that of the wild type.
No significant difference were observed on the primary root length and lateral roots formation in both genotypes grown in presence of mannitol (data not shown). 


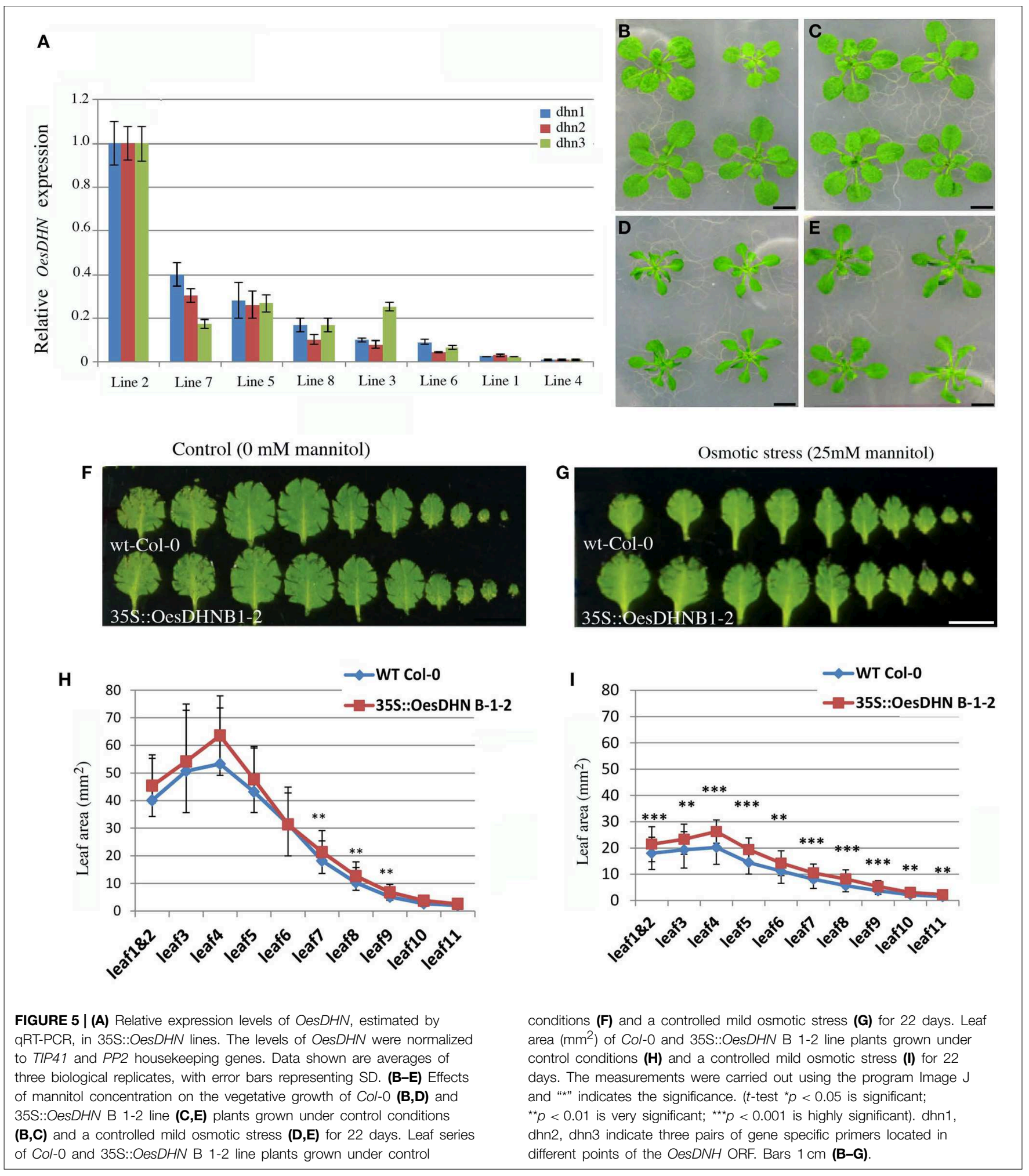

\section{OesDHN Exhibits a Nuclear Localization}

To define the subcellular localization of OesDHN, Arabidopsis 35S::GFP:OesDHN and 35S::OesDHN:GFP T3 lines were generated and OesDHN localization was

performed by confocal microscope on 8 old days seedlings of the 35S::OesDHN:GFP A 4-1, 35S::GFP:OesDHN C115 lines, exhibiting the highest levels of gene expression (Figure 6A). 

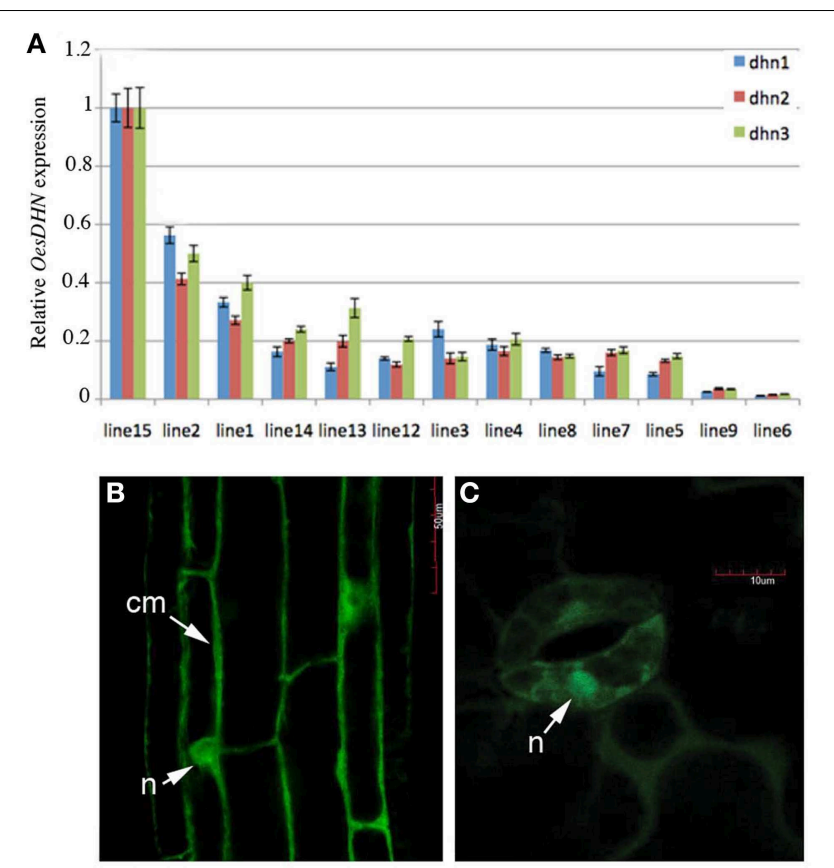

FIGURE 6 | (A) Relative expression levels of OesDHN, estimated by qRT-PCR, in 35S::OesDHN:GFP lines. The levels of OesDHN were normalized to TIP41 and PP2 housekeeping genes. Data shown are averages of three biological replicates, with error bars representing SD. (B,C) subcellular localization of the OesDHN protein fused in $N$ and C-terminal GFP under the control of the CaMV35S promoter in stable T2 35S::OesDHN:GFP line A 4-1, 35S::GFP:OesDHN line C11-5 lines of Arabidopsis with one T-DNA locus. (B) Root maturation zone; (C) Guard cells of stomata, located on the abaxial side of leaves. cm, cell membrane; $\mathrm{n}$, nucleus. dhn1, dhn2, dhn3 indicate three pairs of gene specific primers located in different points of the OesDNH ORF.

OesDHN presence was observed in the cytosol near the putative cell membrane and clearly in the nucleus in the epidermis of primary roots and guard cells of stomata (Figures 6B,C). This last result is consistent with in silico characterization, indicating the presence of a nuclear localization signal peptide.

\section{Discussion}

Understanding the molecular mechanisms that allow plants to cope with abiotic stress can help to manipulate plant breeding with the aim to improve their tolerance and adaptation and preserve their productivity. Currently, drought is among major abiotic stresses impacting on plant development and productivity. Therefore, in the present study we focused our attention on DHNs, a protein family known to play a protective role during dehydration process induced by either developmental cues, such as embryo maturation, pollen development and bud dormancy, or different environmental factors including drought, salinity heat and cold (Gilmour et al., 1992; Nylander et al., 2001; Ali-Benali et al., 2005; Brini et al., 2007, 2010; Hanin et al.,
2011; Tripepi et al., 2011). So far, the precise role of DHNs in plants has not yet been fully defined. At this respect, we may recall that due to their intrinsically disordered structure DHNs are prevented from denaturation and exhibit high flexibility, structural adaptability and extended conformations (Tompa, 2002; Bokor et al., 2005; Mouillon et al., 2008; Cuevas-Velazquez et al., 2014).

Consistently with these characteristics, DHNs have been found to bind to divalent cations and other macromolecules, such as proteins, nucleic acid and negatively charged lipids (Campbell and Close, 1997; Waterer et al., 2010). Based on all these features, numerous activities have been suggested for DHNs, including buffering water, sequestering ions, acting as space filler, stabilizing membranes and cellular structural components, preventing enzyme inactivation by protein-protein interaction or acting as chaperones and molecular shields in response to the different stresses (Ouellet et al., 1993; Hara et al., 2005; Kovacs et al., 2008; Brini et al., 2010; Cuevas-Velazquez et al., 2014). More recently, a reduction of stomatal density has been observed in transgenic Arabidopsis plants overexpressing $M t C A S 31$ through the interaction with the ICE1 transcription factor (Xie et al., 2012).

On the other hand, a positive relationship between the expression levels of DHNs transcripts or proteins and plant stress tolerance has been verified and usually more tolerant genotypes or cultivars have higher levels of DHNs than the less tolerant ones (Porat et al., 2004; Kosovà et al., 2010). Moreover, in different species heterologousexpression of DHNs genes, was found to confer tolerance to drought, cold and salinity (Hara et al., 2003; Rorat et al., 2006; Choudhury et al., 2007). For example, Nicotiana tabacum transgenic plants overexpressing Citrus unshiu COR19 gene exhibited increased cold tolerance (Hara et al., 2003) as well as tolerance to water deficit and salinity was induced in transgenic plants of Oryza sativa overexpressing both Hordeum vulgare HVA1 (Xu et al., 1996) and wheat PMA80 and PMA1959 genes (Cheng et al., 2002). Furthermore, an enhanced tolerance to osmotic stresses was also observed in Arabidopsis transgenic plants overexpressing the dehydrin DHN-5 of Triticum durum (Brini et al., 2010). Based on all these results, DHNs feature as useful tool to develop stress tolerance traits and this prompted us to enlarge information on this protein family.

In this context, we isolated and characterized a novel $D H N$ gene from oleaster plants which is a prevalent component of evergreen vegetation that extends along the coastal and subcoastal areas in the Mediterranean, due to a high photosynthetic efficiency and drought tolerance (Bacchetta et al., 2003; Mulas et al., 2011). The gene was named OesDHN and includes an intron sequence within the $S$ segment, a feature observed in other DHNs of both angiosperms and gymnosperms (Perdiguero et al., 2012, 2014; Jiménez-Bremont et al., 2013). The deduced amino acid sequence showed the typical lysine-rich $\mathrm{K}$ domain of angiosperm DHNs, and both homology and phylogenetic analyses categorized OesDHN as an $\mathrm{SK}_{2}$-type DHN (Mundy and Chua, 1988; Close, 1996, 1997). Moreover, a nuclear target sequence, marked by the KKKK motif, was identified in the NLS region of OesDHN. Such predicted nuclear localization was then confirmed by laser confocal analysis, 
performed on 35S::OesDHN:GFP A 4-1 and 35S::GFP:OesDHN C11-5 Arabidopsis transgenic lines, showing the presence of OesDHN protein inside the nucleus, This result is consistent with the nuclear localization detected for other DHNs, such as wheat DHN-5 and maize RAB17 proteins (Riera et al., 2004; Brini et al., 2007). Noteworthy, the nucleo-cytoplasmic distribution of DHNs is supposed to depend on protein phosphorylation status, which in turn can be controlled by stress conditions (Goday et al., 1994; Alsheikh et al., 2003; Brini et al., 2007; Mehta et al., 2009).

Additionally, OesDHN protein was found also near the plasma membrane (Figure 6B). A similar localization has been observed for other SKn and KnS DHNs while it has been never reported for DHNs with the Y consensus (Hara et al., 2003; Xu et al., 2014). Thus, our results support the hypothesis that only the K segment is responsible for binding to membrane (Koag et al., 2009) and together with $S$ segments exert a role in membrane protection (Graether and Boddington, 2014).

Concerning OesDHN expression pattern, it must be underlined that, although only at the transcript levels, for the first time the putative activity of a $\mathrm{SK}_{2}$-type $\mathrm{DHN}$ has been localized at the organ/tissue level (Graether and Boddington, 2014). In particular, we observed that in oleaster plants OesDHN is expressed in all organs, although at very different levels. Based on the suggested role of $\mathrm{SK}_{2}$-type DHNs (Kosova et al., 2010), such expression pattern could be related to tolerance traits of oleaster able to grow under multiple stress condition such as high salinity, high temperature and intense solar irradiance (Bacchetta et al., 2003; Mulas et al., 2011). Moreover, it must be mentioned that, although in some cases, expression is confined to specific organs or developmental stage, constitutive expression of DHNs has been commonly observed in both herbaceous and woody plants (Hara et al., 2001; Wang et al., 2007, 2011, 2014).

We also demonstrated that OesDHN expression is modulated during leaf development (i.e., it is higher in mature than in young leaves), and enhanced in the leaf and stem of oleaster plants exposed to mild water deficit. Under mild drought stress an increase of DHNs presence in leaf tissues was also observed through cyto-immunological analysis (Figure $2 S$ ) indicating that in oleaster plants defense mechanisms are enhanced at both transcriptional and post-transcriptional level. This result is in agreement with data in literature showing that DHNs highly accumulated in vegetative tissues of plants subjected to cellular dehydration, providing a protective mechanism (Brini et al., 2007, 2010). Notably, under mild drought stress the increased level of OesDHN transcripts and protein in the leaf was coupled to a well-preserved tissue organization, despite the water deficit. This result appears fully consistent with the role of space filler proposed for DHNs (Battaglia et al., 2008).

Finally, to confirm the involvement of OesDHN in plant stress response, its function was investigated by expressing it in Arabidopsis plants via the CaMV $35 \mathrm{~S}$ promoter. We observed that these transgenic lines engineered to overexpress the OesDHN showed a better tolerance to osmotic stress than wild-type plants. This result fulfills other evidences showing that in transgenic plants DHNs expression is positively related to an increased tolerance to different stresses such as drought and salinity beside cold (Hara et al., 2003; Choudhury et al., 2007; Wang et al., 2011). In this context, it must be underlined that the involvement of DHNs in the protective system against osmotic stress is also supported by the up-regulation of $D H N$ transcripts usually found upon salt or ABA treatment (Nylander et al., 2001; Sanchez-Ballesta et al., 2004). ABA is a phytohormone triggered by a multitude of abiotic stresses including drought, salinity, desiccation, and wounding and represents the major physiological signal that induces responses to drought and high salinity in plants (Gilmour et al., 1992; Lata and Prasad, 2011). Interestingly, our analysis of OesDHN promoter region highlighted the presence of different cis-elements involved in drought tolerance and the presence, among them, of an ABRE element suggests that Oes DHN could act as an ABA-responsive protein (Abe et al., 2003; Lata and Prasad, 2011).

In conclusion, we demonstrated that OesDHN expression is induced by drought stress and is able to confer osmotic stress tolerance. Based on gene characterization and protein localization we also propose that, as reported for other dehydrins and LEA proteins (Dure, 1993; Riera et al., 2004; Brini et al., 2007) OesDHN, interacting with distinct cellular components, could be involved in cell protection under water deficit and osmotic stress likely through an ABA-dependent pathway.

\section{Author Contributions}

$\mathrm{AC}, \mathrm{AM}, \mathrm{LB}, \mathrm{MV}$, and $\mathrm{MB}$ designed research; AC, AM, and LB performed research; AC, AM, LB, MV, and MB analyzed data and discussed results; $\mathrm{AC}$ and $\mathrm{MB}$ wrote the paper. All authors contributed to improving the paper and approved the final manuscript.

\section{Acknowledgments}

This work was founded by grant from University of Calabria (MIUR-ex60\%) to MB and AC. AM is indebted to PON SPREAD BIO-OIL project from European Union (EU) for a postdoctoral fellowship.

\section{Supplementary Material}

The Supplementary Material for this article can be found online at: http://journal.frontiersin.org/article/10.3389/fpls.2015. 00392

Figure 1S | Schematic representation of the 35S::OesDHN, 35S::OesDHN:GFP and 35S::GFP:OesDHN binary expression vectors. LB, left border; RB, right border; Pnos, nopaline synthase promoter; Kan, kanamycin gene; Tnos, termination signal of nopaline synthase gene; P35S, CaMV 35 S promoter; OesDHN Olea, cDNA coding for putative dehydrin; Egfp, Aequorea victoria synthetic green fluorescent protein gene; T35S, termination signal of CaMV 35S gene; attB1, attB2, modified bacteriophage $k$ attachment sites.

Figure 2S | In situ localization of dehydrin-like proteins on cross sections of mature leaves (length $2.5 \pm 0.3 \mathrm{~cm}$ ) grown in pots under control condition (A,B) and exposed to a SWC of $\mathbf{4 5 \%}(\mathrm{C}, \mathrm{D})$. $n$, nucleus; arrowhead indicate nuclear signal. Bars $25 \mu \mathrm{m}$ (C-E); $43 \mu \mathrm{m}$ (F); $28 \mu \mathrm{m}$ (A,C); $40 \mu \mathrm{m}$ (B,D); $90 \mu \mathrm{m}$ (E) 


\section{References}

Abe, H., Urao, T., Ito, T., Seki, M., Shinozaki, K., and Yamaguchi-Shinozaki, K. (2003). Arabidopsis AtMYC2 (bHLH) and AtMYB2 (MYB) function as transcriptional activators in abscisic acid signaling. Plant Cell 15, 63-78. doi: 10.1105/tpc.006130

Ahuja, I., De Vos, R. C. H., Bones, A. M., and Hall, R. D. (2010). Plant molecular stress responses face climate change. Trends Plant Sci. 12, 664-674. doi: 10.1016/j.tplants.2010.08.002

Ali-Benali, M. A., Alary, R., Joudrier, P., and Gautier, M. F. (2005). Comparative expression of five Lea genes during wheat seed development and in response to abiotic stresses by real-tim quantitative RT-PCR. Biochem. Biophys. Acta 1730, 56-65. doi: 10.1016/j.bbaexp.2005.05.011

Allagulova, C. R., Gimalo, F. R., Shakirova, F. M., and Vakhitov, V. A. (2003). The plant dehydrins. Structure putative functions. Biochemistry (Mosc) 68, 945-951.

Alsheikh, M. K., Heyen, B. J., and Randall, S. K. (2003). Ion binding properties of the dehydrin ERD14 are dependent upon phosphorylation. J. Biol. Chem. 278, 40882-40889. doi: 10.1074/jbc.M307151200

Bacchetta, G., Bagella, S., Biondi, E., Farris, E., Filigheddu, R., and Mossa, L. (2003). $\mathrm{Su}$ alcune formazioni a Olea europaea L. var. sylvestris Brot. della Sardegna. Fitosociologia 40, 49-53.

Battaglia, M., Olvera-Carrillo, Y., Garciarrubio, A., Campos, F., and Covarrubias, A. C. (2008). The enigmatic LEA proteins and other hydrophilins. Plant Physiol. 148, 6-24. doi: 10.1104/pp.108.120725

Bies-Etheve, N., Gaubier-Comella, P., Debures, A., Lasserre, E., Jobet, E., Raynal, M., et al. (2008). Inventory, evolution and expression profiling diversity of the LEA (late embryogenesis abundant) protein gene family in Arabidopsis thaliana. Plant Mol. Biol. 67, 107-124. doi: 10.1007/s11103-008-9304-x

Bokor, M., Csizmok,V., Kovacs, D., Banki, P., Friedrich, P., Tompa, P., et al. (2005). NMR relaxation studies on the hydrate layer of intrinsically unstructured proteins. Biophys. J. 88, 2030-2037. doi: 10.1529/biophysj.104. 051912

Brini, F., Hanin, M., Lumbreras, V., Irar, S., Pages, M., and Masmoudi, K. (2007). Functional characterization of DHN-5, a dehydrin showing a differential phosphorylation pattern in two Tunisian durum wheat (Triticum durum Desf.) varieties with marked difference in salt and drought tolerance. Plant Sci. 172, 20-28. doi: 10.1016/j.plantsci.2006.07.011

Brini, F., Saibi, W., Hanin, M., Amara, I., Gargouri, A., and Masmoudi, K. (2010). The wheat dehydrin DHN-5 exerts a heat-protective effect on $\beta$-glucosidase and glucose oxidase activities. Biosci. Biotech. Biochem. 74, 1050-1054. doi: 10.1271/bbb.90949

Bruno, L., Chiappetta, A., Muzzalupo, I., Gagliardi, C., Iaria, D., Bruno, A., et al. (2009). Role of geranylgeranyl reductase gene in organ development and stress response in olive (Olea europaea) plants. Funct. Plant Biol. 36, 370-381. doi: 10.1071/FP08219

Bruno, L., Spadafora, N. D., Iaria, D., Chiappetta, A., and Bitonti, M. B. (2014). Developmental stimuli and stress factors affect expression of ClGLP1, an emerging allergen-related gene in Citrus limon. Plant Physiol. Biochem. 79, 31-40. doi: 10.1016/j.plaphy.2014.03.003

Campbell, S. A., and Close, T. J. (1997). Dehydrins: genes, proteins and association with phenotypic traits. New Phytol. 137, 61-69. doi: 10.1046/j.14698137.1997.00831.x

Carjuzaa, P., Castellión, M., Distéfano, A. J., Del Vas, M., and Maldonado, S. (2008). Detection and subcellular localization of dehydrin-like proteins in quinoa (Chenopodium quinoa Willd) embryos. Protoplasma 233, 149-156. doi: 10.1007/s00709-008-0300-4

Ceccarelli, S., Grando, S., and Baum, M. (2007). Participatory plant breeding in water-limited environments. Exp. Agric. 43, 411-435. doi: 10.1017/s0014479707005327

Cheng, Z., Targolli, J., Huang, X., and Wu, R. (2002). Wheat LEA genes, PMA80 and PMA1959, enhance dehydration tolerance of transgenic rice (Oryza sativa L.). Mol. Breed 10, 71-82. doi: 10.1023/A:1020329401191

Choi, D. W., Zhu, B., and Close, T. J. (1999). The barley (Hordeum vulgare L.) dehydrin multigene family: sequences, allele types, chromosome assignments, and expression characteristics of $11 \mathrm{Dhn}$ genes of cv Dicktoo. Theoret. Appl. Gen. 8, 1234-1247. doi: 10.1007/s001220051189

Choudhury, A. R., Roy, C., and Sengupta, D. N. (2007). Transgenic tobacco plants overexpressing the heterologous lea gene Rab16A from rice during high salt and water deficit display enhanced tolerance to salinity stress. Plant Cell Rep. 26, 1839-1859. doi: 10.1007/s00299-007-0371-2

Close, T. J. (1996). Dehydrins: emergence of a biochemical role of a family of plant dehydration proteins. Physiol. Plant. 97, 795-803. doi: 10.1111/j.13993054.1996.tb00546.x

Close, T. J. (1997), Dehydrins: a commonality in the response of plants to dehydration and low temperature. Physiol. Plant. 100, 291-296. doi: 10.1111/j.1399-3054.1997.tb04785.x

Close, T. J., Kortt, A. A., and Chandler, P. M. (1989). A cDNA-based comparison of dehydration-induced proteins (dehydrins) in barley and corn. Plant Mol. Biol. 13, 95-108. doi: 10.1007/BF00027338

Close, T. J., Meyer, N. C., and Radik, J. (1995).Nucleotide sequence of a gene encoding a 58.5-kilodalton barley dehydrin that lacks a serine tract. Plant Physiol. 107, 289-290. doi: 10.1104/pp.107.1.289

Clough, S. J., and Bent, A. F. (1998). Floral dip: a simplified method for Agrobacterium-mediated transformation of Arabidopsis thaliana. Plant J. 16, 735-743. doi: 10.1046/j.1365-313x.1998.00343.x

Cuevas-Velazquez, C. L., Rendón-Luna, D. F., and Covarrubias, A. A. (2014). Dissecting the cryoprotection mechanisms for dehydrins. Front. Plant Sci. 5:583. doi: $10.3389 /$ fpls. 2014.00583

Czechowski, T., Stitt, M., Altmann, T., Udvardi, M. K., and Scheible, W. R. (2005). Genome-wide identification and testing of superior reference genes for transcript normalization in Arabidopsis. Plant Physiol. 139, 5-17. doi: 10.1104/pp.105.063743

Danyluk, J., Perron, A., Houde, M., Limin, A., Fowler, B., Benhamou, N., et al. (1998). Accumulation of an acidic dehydrin in the vicinity of the plasma membrane durino cold acclimation of wheat. Plant Cell 10, 623-638. doi: $10.1105 /$ tpc.10.4.623

Davis, A. M., Hall, A., Millar, A., Darrah, C., and Davis, S. J. (2009). Protocol: streamlined sub-protocols for floral-dip transformation and selection of transformants in Arabidopsis thaliana. Plant Methods 5, 3-10. doi: $10.1186 / 1746-4811-5-3$

Dure, L. (1993). "Structural motifs in LEA proteins of higher plants," in Plants Responses to Cellular Dehydration During Environmental Stress, eds L. Dure, T. J. Close, and E. A. Bray (Rockville, MD: American Society of Plant Physiology), 91-103.

Gilmour, S. J., Artus, N. N., and Thomashow, M. F. (1992). cDNA sequence analysis and expression of two cold -regulated genes of Arabidopsis thaliana. Plant Mol. Biol. 18, 13-21. doi: 10.1007/BF00018452

Goday, A., Jensen, A. B., Culianez-Macia, F. A., Alba, M. M., Figueras, M., and Serratosa, J., et al. (1994). The maize abscisic acid-responsive protein rab17 is located in the nucleus and interacts with nuclear localization signals. Plant Cell 6, 351-360. doi: $10.1105 /$ tpc.6.3.351

Graether, S. P., and Boddington, K. F. (2014). Disorder and function: a review of the dehydrin protein family. Front. Plant Sci. 5:576. doi: 10.3389/fpls.2014.00576

Hanin, M., Brini, F., Ebel, C., Toda, Y., Takeda, S., and Masmoudi, K. (2011). Plant dehydrins and stress tolerance -versatile proteins for complex mechanisms. Plant Sign. Behav. 6, 1503-1509. doi: 10.4161/psb.6.10.17088

Hara, M., Fujinaga, M., and Kuboi, T. (2005). Metal binding by citrus dehydrin with histidine-rich domains. J. Exp. Bot. 56, 2695-2703. doi: 10.1093/jxb/eri262

Hara, M., Terashima, S., Fukaya, T., and Kuboi, T. (2003). Enhancement of cold tolerance and inhibition of lipid peroxidation by citrus dehydrin in transgenic tobacco. Planta 217, 290-298. doi: 10.1007/s00425-003-0986-7

Hara, M., Terashima, S., and Kuboi, T. (2001). Characterization and cryoprotective activity of cold-responsive dehydrin from Citrus unshiu. J. Plant Physiol. 158, 1333-1336. doi: 10.1078/0176-1617-00600

Harauz, G., and Libich, D. S. (2009). The classic basic protein of myelin - conserved structural motifs and the dynamic molecular barcode involved in membrane adhesion and protein-protein interactions. Curr. Prot. Pept. Sci. 10, 196-215. doi: $10.2174 / 138920309788452218$

Hundertmark, M., and Hincha, D. K. (2008). LEA (Late Embryogenesis Abundant) proteins and their encoding genes in Arabidopsis thaliana. BMC Gen. 9:118. doi: 10.1186/1471-2164-9-118

Jiménez-Bremont, J. F., Maruri-López, I., Ochoa-Alfaro, A. E., Delgado-Sánchez, P., Bravo, J., and Rodríguez-Kessler, M. (2013). LEA gene introns: is the intron of dehydrin genes a characteristic of the serine-segment? Plant Mol. Biol. Rep. 31, 128-140. doi: 10.1007/s11105-012-0483-x 
Karimi, M., Inzé, D., and Depicker, A. (2002). GATEWAY vectors for Agrobacterium-mediated plant transformation. Trends Plant Sci. 7, 193-195. doi: 10.1016/S1360-1385(02)02251-3

Karlson, D. T., Fujino, T., Kimura, S., Baba, K., Itoh, T., and Ashworth, E. N. (2003). Novel plasmodesmata association of dehydrin-like proteins in cold acclimated red-osier dogwood (Cornus sericea). Tree Physiol. 23, 759-767. doi: 10.1093/treephys/23.11.759

Koag, M. C., Wilkens, S., Fenton, R. D., Resnik, J., Vo, E., and Close, T. J. (2009). The K-segment of maize DHN1 mediates binding to anionic phospholipid vesicles and concomitant structural changes. Plant Physiol. 150, 1503-1514. doi: 10.1104/pp.109.136697

Kosovà, K., Prasil, I. T., Prasilovà, P., Vitàmvàs, P., and Chrpovà, J. (2010). The development of frost tolerance and DHN5 protein accumulation in barley (Hordeum vulgare) doubled haploid lines derived from Atlas 68 $x$ Igri cross during cold acclimation. J. Plant Physiol. 167, 343-350. doi: 10.1016/j.jplph.2009.09.020

Kovacs, D., Kalmar, E., Torok, Z., and Tompa, P. (2008). Chaperone activity of ERD10 and ERD14, two disordered stress related plant proteins. Plant Physiol. 147, 381-390. doi: $10.1104 /$ pp.108.118208

Lata, C., and Prasad, M. (2011). Role of DREBs in regulation of abiotic stress responses in plants. J. Exp. Bot. 62, 4731-4748. doi: 10.1093/jxb/err210

Layton, B. E., Boyd, M. B., Tripepi, M. S., Bitonti, M. B., Norman, M., and Dollahon, R. (2010). Dehydration-induced expression of a 31-kda dehydrin in Polypodium Polypodioides (Polypodiaceae) may enable large, reversible deformation of cell walls. Am. J. Bot. 97, 535-544. doi: 10.3732/ajb.0900285

Lee, S. C., Lee, M. Y., Kim, S. J., Jun, S. H., An, G., and Kim, S. R. (2005). Characterization of an Abiotic Stress-inducible Dehydrin Gene, OsDhn1, in Rice (Oryza sativa L.). Mol. Cells 19, 212-218.

Lescot, M., Dehais, P., Thijs, G., Marchal, K., Moreau, Y., Peer, Y. V., et al. (2002). PlantCARE, a database of plant cis-acting regulatory elements and a portal to tools for in silico analysis of promoter sequences. Nucleic Acid Res. 30, 325-327. doi: $10.1093 / \mathrm{nar} / 30.1 .325$

Liu, C. C., Li, C. M., Liu, B. G., Ge, S. J., Dong, X. M., and Li, W. (2012). Genomewide identification and characterization of a dehydrin gene family in poplar (Populus trichocarpa). Plant Mol. Biol. Rep. 30, 848-859. doi: 10.1007/s11105011-0395-1

Livak, K. J., and Schmittgen, T. D. (2001). Analysis of relative gene expression data using real- time quantitative PCR and the $2^{-\Delta \Delta C T}$ method. Methods 25, 402-408. doi: 10.1006/meth.2001.1262

Meehl, G. A., Stocker, T. F., Collins, W. D., Friedlingstein, P., Gaye, A. T., and Gregory, J. M. (2007). "Global climate projections," in Climate Change, eds S. Solomon, D. Qin, M. Manning, Z. Chen, M. Marquis, K. B. Averyt, M. Tignor, and H. L. Miller (Cambridge, UK: Cambridge University Press), 749-845.

Mehta, P. A., Rebala, K. C., Venkataraman, G., and Parida, A. (2009). A diurnally regulated dehydrin from Avicennia marina that shows nucleo-cytoplasmic localization and is phosphorylated by Casein kinase II in vitro. Plant Physiol. Biochem. 47, 701-709. doi: 10.1016/j.plaphy.2009.03.008

Mouillon, J. M., Eriksson, S. K., and Harryson, P. (2008). Mimicking the plant cell interior under water stress by macromolecular crowding: disordered dehydrin proteins are highly resistant to structural collapse. Plant Physiol. 148, 1925-1937. doi: 10.1104/pp.108.124099

Mulas, M., Mura, G., Dessena, L., Bandino, G., and Sedda, P. (2011). L'oleastro come potenziale riserva di geni agronomicamente utili. Acta Italus Hort. 1, 91-93.

Mundy, J., and Chua, N. H. (1988). Abscisic acid and water-stress induce the expression of a novel rice gene. EMBO J. 17, 2279-2286.

Murashige, T., and Skoog, F. (1962). A revised medium for rapid growth and bio assays with tobacco tissue cultures. Physiol. Plant. 15, 473-497. doi: 10.1111/j.1399-3054.1962.tb08052.x

Murray, M. G., and Thompson, W. F. (1980). Rapid isolation of high-molecularweight plant DNA. Nucleic Acids Res. 8, 4321-4325. doi: 10.1093/nar/8.19.4321

Nylander, M., Svensson, J., Palva, E. T., and Welin, B. V. (2001). Stressinduced accumulation and tissue specific localization of dehydrins in Arabidopsis thaliana. Plant Mol. Biol. 45, 263-279. doi: 10.1023/A:1006469 128280

Ouellet, F., Houde, M., and Sarhan, F. (1993). Purification, characterization and cDNA cloning of the $200 \mathrm{kDa}$ protein induced by cold acclimation in wheat. Plant Cell Physiol. 34, 59-65.
Perdiguero, P., Barbero, M. C.,Cervera, M. T.,Soto, Á., and Collada C. (2012). Novel conserved segments are associated with differential expression patterns for Pinaceae dehydrins. Planta 236, 1863-1874. doi: $10.1007 / \mathrm{s} 00425-012-1737-4$

Perdiguero, P., Collad, C., and Soto, Á. (2014). Novel dehydrins lacking complete K-segments in Pinaceae. The exception rather than the rule. Front. Plant Sci. 6:682. doi: $10.3389 /$ fpls.2014.00682

Porat, R., Pasentsis, K., Rozentzvieg, D., Gerasopoulos, D., Falara, V., Samac, A., et al. (2004). Isolation of a dehydrin cDNA from orange and grapefruit citrus fruit that is specifically induced by the combination of heat followed by chilling temperatures. Physiol. Plant. 120, 256-264. doi: 10.1111/j.00319317.2004.0242.x

Rath, A., Davidson, A. R., and Deber, C. M. (2005). The structure of "unstructured" regions in peptides and proteins: role of the polyproline II helix in protein folding and recognition. Biopolymers 80, 179-185. doi: 10.1002/bip. 20227

Receveur-Bréchot, V., Bourhis, J.-M., Uversky, V. N., Canard, B., and Longhi, S. (2005). Assessing protein disorder and induced folding. Proteins 62, 24-45. doi: 10.1002/prot.20750

Riera, M., Figueras, M., Lopez, C., Goday, A., and Pages, M. (2004). Protein kinase CK2 modulates developmental functions of the abscisic acid responsive protein Rab17 from maize. Proc. Natl. Acad. Sci. U.S.A. 101, 9879-9884. doi: 10.1073/pnas.0306154101

Rorat, T., Grygorowicz, W. J., Irzykowski, W., and Rey, P. (2004). Expression of KS-type dehydrins is primarily regulated by factors related to organ type and leaf developmental stage during vegetative growth. Planta 218, 878-885. doi: 10.1007/s00425-003-1171-8

Rorat, T., Szabala, B. M., Grygorowicz, W. J., Wojtowicz, B., Yin, Z., and Rey, P. (2006). Expression of SK3-type dehydrin in transporting organs is associated with cold acclimation in Solanum species. Planta 224, 205-221. doi: 10.1007/s00425-005-0200-1

Sakuma, Y., Maruyama, K., Osakabe, Y., Qin, F., Seki, M., Shinozaki, K., et al. (2006). Functional analysis of an Arabidopsis transcription factor, DREB2A, involved in drought-responsive gene expression. Plant Cell 18, 1292-1309. doi: 10.1105/tpc.105.035881

Sanchez-Ballesta, M. T., Rodrigo, M. J., Lafuente, M. T., Granella, A., and Zacarias, L. (2004). Dehydrin from citrus, which confers in vitro dehydration and freezing protection activity, is constitutive and highly expressed in the flavedo of fruit but responsive to cold and water stress in leaves. J. Agric. Food Chem. 52, 1950-1957. doi: 10.1021/jf035216+

Skinner, J. S., Von Zitzewitz, J., Szücs, P., Marquez-Cedillo, L., Filichkin, T., Amundsen, K. E. J., et al. (2005). Structural, functional, and phylogenetic characterization of a large CBF gene family in barley. Plant Mol. Biol. 59, 533-551. doi: 10.1007/s11103-005-2498-2

Skirycz, A., De Bodt, S., Obata, T., De Clercq, I., Claeys, H., De Rycke, R., et al. (2010). Developmental stage specificity and the role of mitochondrial metabolism in the response of Arabidopsis leaves to prolonged mild osmotic stress. Plant Physiol. 152, 227-244. doi: 10.1104/pp.109.148965

Svensson, J. T., Crosatti, C., Campoli, C., Bassi, R., Stanca, A. M., Close, T. J., et al. (2006). Transcriptome analysis of cold acclimation in barley albina and xantha mutants. Plant Physiol. 141, 257-270. doi: 10.1104/pp.105.072645

Tamura, K., Dudley, J., Nei, M., and Kumar, S. (2007). Molecular evolutionary genetics analysis (MEGA) software version 4.0. Mol. Biol. Evol. 24, 1596-1599. doi: 10.1093/molbev/msm092

Tommasini, L., Svensson, J. T., Rodriguez, E. M., Wahid, A., Malatrasi, M., Kato, K., et al. (2008). Dehydrin gene expression provides an indicator of low temperature and drought stress: transcriptome-based analysis of Barley (Hordeum vulgare L.). Funct. Integr. Genomics 8, 387-405. doi: 10.1007/s10142008-0081-z

Tompa, P. (2002). Intrinsically unstructured proteins. Trends Biochem. Sci. 27, 527-533. doi: 10.1016/S0968-0004(02)02169-2

Tripepi, M., Pöhlschroder, M., and Bitonti, M. B. (2011). Diversity if dehydrins in Olea europaea plants exposed to stress. Open Plant Sci. J. 5, 9-13. doi: $10.2174 / 1874294701105010009$

Velasco, R., Zharkikh, A., Troggio, M., Cartwright, D. A., Cestaro, A., Pruss, D., et al. (2007). A high quality draft consensussequence of the genome of a heterozygous grapevine variety. PLOS ONE 2:e1326. doi: 10.1371/journal.pone.0001326 
Wang, X. S., Zhu, H. B., Jin, G. L., Liu, H. L., Wu, W. R., and Zhu, J. (2007). Genome-scale identification and analysis of LEA genes in rice (Oryza sativa L.). Plant Sci. 172, 414-420. doi: 10.1016/j.plantsci.2006.10.004

Wang, Y., Wang, H., Li, R., Ma, Y., and Wei, J. (2011). Expression of a SK2-type dehydrin gene from Populus euphratica in a Populus tremula $\times$ Populus alba hybrid increased drought tolerance. Afr. J. Biotech. 10, 9225-9232. doi: 10.5897/ AJB10.1196

Wang, Y., Xu, H., Zhu, H., Tao, Y., Zhang, G., and Zhang, L. (2014). Classification and expression diversification of wheat dehydrin genes. Plant Sci. 214, 113-120. doi: 10.1016/j.plantsci.2013.10.005

Waterer, D., Benning, N. T., Wu, G. H., Luo, X. M., Liu, X. J., and Gusta, M. (2010). Evaluation of abiotic stress tolerance of genetically modified potatoes (Solanum tuberosum cv. Desiree). Mol. Breed. 25, 527-540. doi: 10.1007/s11032-009-9351-2

Xie, C., Zhang, R., Qu, Y., Miao, Z., Zhang, Y., Shen, X., et al. (2012). Overexpression of MtCAS31 enhances drought tolerance in transgenic Arabidopsis by reducing stomatal density. NewPhytol. 195, 124-135. doi: 10.1111/j.1469-8137.2012.04136.x

Xu, D., Duan, X., Wang, B., Hong, B., Ho, T. H. D., and Wu, R. (1996). Expression of a late embryogenesis abundant protein gene, HVA1, from barley confers tolerance to water deficit and salt stress in transgenic rice. Plant Physiol. 110, 249-257.

Xu, H., Yang, Y., Xie, L., Li, X., Feng, C., Chen, J., et al. (2014). Involvement of multiple types of dehydrins in the freezing response in loquat (Eriobotrya japonica). PLoS ONE 9:e87575. doi: 10.1371/journal.pone.0087575
Yamaguchi-Shinozaki, K., and Shinozaki, K. (2006). Transcriptional regulatory networks in cellular responses and tolerance to dehydration and cold stresses. Ann. Rev. Plant Biol. 57, 781-803. doi: 10.1146/annurev.arplant.57.032905.105444

Yokoyama, R., and Nishitani, K. (2001). A comprehensive expression analysis of all members of a gene family encoding cell-wall enzymes allowed us to predict cis-regulatory regions involved in cell-wall construction in specific organs of Arabidopsis. Plant Cell Physiol. 42, 1025-1033. doi: 10.1093/pcp/ pce154

Zhu, J. K. (2002). Salt and drought stress signal transduction in plants. Ann. Rev. Plant Biol. 53, 247-273. doi: 10.1146/annurev.arplant.53.091401.143329

Zohary, D., and Spiegel-Roy, P. (1975). Beginnigs of fruit growing in the old world. Science 187, 319-327. doi: 10.1126/science.187.4174.319

Conflict of Interest Statement: The authors declare that the research was conducted in the absence of any commercial or financial relationships that could be construed as a potential conflict of interest.

Copyright $\odot 2015$ Chiappetta, Muto, Bruno, Woloszynska, Van Lijsebettens and Bitonti. This is an open-access article distributed under the terms of the Creative Commons Attribution License (CC BY). The use, distribution or reproduction in other forums is permitted, provided the original author(s) or licensor are credited and that the original publication in this journal is cited, in accordance with accepted academic practice. No use, distribution or reproduction is permitted which does not comply with these terms. 